This work is licensed under a Creative Commons Attribution 4.0 International License. Ovaj rad dostupan je za upotrebu pod licencom Creative Commons Imenovanje 4.0 međunarodna.

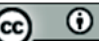

Alen Albin ŠIRCA

UDK 7.034.7

Filozofska fakulteta Ljubljana

7.035 .4

Aškerčeva 2

141.33

1000 Ljubljana, Slovenija

alen.albin.sirca@ff.uni-lj.si

DOI: https://doi.org/10.29162/ANAFORA.v6i1.10

Izvorni znanstveni članak

Original Research Article

Primljeno 22. veljače 2019.

Received: 22 February 2019

Prihvaćeno 7. svibnja 2019.

Accepted: 7 May 2019

\title{
BAROK KAO KULTUROLOŠKI KONCEPT
}

\section{Sažetak}

Nakon što je Heinrich Wölfflin uveo pojam baroka u povijest umjetnosti, taj se izraz brzo proširio na sva područja humanistike, nalazeći svoje mjesto i u znanosti o književnosti. Usporedno s takvim, u osnovi historijskim razumijevanjem, od Nietzscheova se doba razvijalo i transhistorijsko shvaćanje baroka kao dekadentnog stila koji se može javiti u svakoj epohi. U posljednjih nekoliko desetljeća književna teorija izrodila je i pojam „neobaroka“, kako bi razjasnila konstrukciju alternativnih povijesti modernosti, imunih na esencijalističku logiku suvremenog kapitalizma. U članku se, nadalje, oslanjam na „heterološku“ interpretaciju modernosti kakvu je razvio francuski teoretičar Michel de Certeau. On je u djelu La Fable mystique (1982) ustvrdio da u baroknoj mističkoj književnosti odlučujuća uloga ne pripada radikalnom prijelomu sa srednjim vijekom, već da je riječ o novom načinu uporabe (re-employment) postojećih diskursa, koji izbjegavaju svako zatvaranje u okvire institucije. Uvjet mogućnosti takvih diskurzivnih strategija je poseban odnos prema radikalnoj drugosti. Iz takvog odnosa ne nastaje stabilni kartezijanski subjektivitet, već subjekt koji biva za drugog/Drugoga. Pretpostavka da je mistična književnost simptom modernosti kao takve utire put uvidu u izvorni, „atopični“ prostor, koji nadilazi puke društvene i političke projekte emancipacije. Tu je riječ o svojevrsnom transcendentalnom razumijevanju modernosti kao uvjeta mogućnosti onog modela subjektivnosti, diskurzivnosti i prakse koji je svagda usmjeren ka jednoj heterološkoj etici.

Ključne riječi: barok, neobarok, modernost, alteritet, Michel de Certeau 


\section{Uvod}

U ovom će ogledu biti govora o baroku, koji je tijekom zadnjih desetljeća u znanosti o književnosti ponovno postao predmetom živahnih raspri. Zapravo, posrijedi je kritički pretres takozvanog neobaroka, koji se nadovezuje na inherentnu dvoznačnost izvornoga poimanja baroka. Već je od Nietzscheova djela, osim povijesnoga shvaćanja toga razdoblja, moguće pratiti i transhistorijsko razumijevanje baroka kao univerzalne estetske pojave, koja se uvijek iznova „vraća“, poput antipoda umjerenom, klasičnom stilu. Većina teoretičara koji zagovaraju neobarok zauzima se i za nekakvo neesencijalističko konstruiranje alternativnih povijesti modernoga doba, pri čemu se autori uglavnom ograničavaju na (post)kolonijalne razmjere Latinske Amerike. Moj je glavni cilj kritika toga koncepta, koji se čini odveć generičan, napose i nedostatno reflektiran, jer u boju protiv esencijalizma sam prerasta u svojevrsni esencijalizam, budući da počiva na kvazimesijanskom vjerovanju u autentični prostor društvene slobode. Stoga se u ovome eseju, radi korektiva takvoj jednostranoj konceptualizaciji neobaroka, oslanjam na heterološko određenje modernosti koje je razvijao Michel de Certeau. Pokušat ću pokazati da je francuski teoretičar u svojem temeljnom djelu La Fable mystique (1982), na primjeru mističke literature, obrazlagao tezu prema kojoj modernost nije uspostavljena radikalnim prijelomom sa srednjovjekovljem, već posezanjem za novim načinima prakticiranja već postojećih diskursa, oslobađajući dimenziju za novi odnos prema radikalnoj drugosti. U nastavku ću braniti postavku po kojoj je takvo shvaćanje modernosti moguće transponirati i na fenomen baroka. Zato „heterološki pojam baroka“ može poslužiti kao alternativa suvremenoj kulturološkoj koncepciji neobaroka. Nasuprot primatu novosti i diskontinuiteta, karakterističnome za postkolonijalno poimanje neobaroka, heteorološko se mišljenje na praktičnoj razini posvećuje taktikama reinterpretacije koje ukazuju i na kontinuitet i na raskid s prethodnim epohama. Osim toga, temeljitom refleksijom vlastitih uvjeta mogućnosti, osobito promišljanjem specifičnog razumijevanja jezika, prostora i subjektivnosti, ovaj heterološki koncept pridonosi većoj senzibilnosti za drugo i drukčije, za ono što se ne da svesti na utopijski diskurs o istinskoj društveno-političkoj emancipaciji.

U metodološkom smislu, pri tematizaciji pojma baroka i neobaroka slijedit ću takozvanu „pojmovnu historiju“ (Begriffsgeschichte), koja nam dopušta pratiti različne povijesne mijene dane kulturne pojave. Potom ću posegnuti i za podrobnim čitanjem (close reading) osnovnih premisa de Certeaujeve heterologije modernosti, koju ću potom aplicirati na estetski fenomen (neo)baroka. U zaključ- 
nom će se odlomku, nadam se, pokazati i hermeneutički učinak cijele rasprave: kritika neobaroka na osnovi de Certeaujeve heterologije moguća je upravo zato jer je heterološko mišljenje neprestano usmjereno na uvjete vlastite pred-postavljenosti, čime izbjegava zamke bezupitnog, dogmatičnog mišljenja totaliteta.

\section{Barok}

Izraz „barok” u povijesti umjetnosti i drugim humanističkim disciplinama od samoga je početka predstavljao ambivalentan pojam: umjetnost označena tim pojmom, počevši od prosvjetiteljskog doba, nerijetko je žigosana kao loša, kao klasično stvaralaštvo koje to uistinu nije; barok je ocjenjivan kao neracionalan i dekadentan stil, na granici bizarnosti, čak perverzije. Ipak, još i koncem XIX. stoljeća, osobito na njemačkom govornom području, zanimanje za baroknu estetiku sve je više raslo, te se taj umjetnički pravac počeo pojavljivati i u vidokrugu sveučilišnog obrazovanja. Švicarski povjesničar umjetnosti Heinrich Wölfflin smatra se prvim autorom koji se istinski i temeljito posvetio tom fenomenu, a vjerojatno je bio i prvi koji mu je pripisivao pozitivnu vrijednost. U svom djelu o renesansi i baroku Renaissance und Barock Wölfflin bilježi da je barokno stvaralaštvo moguće misliti u živoj usporedbi s razvojem antičke umjetnosti: kao što se klasično, „zlatno doba” antike izopačuje i postaje postklasično „srebrno doba”, i novovjekovna se renesansa preobražava u barok. Dakako, taj preobražaj za Wölfflina nije sinonim patološke dekadencije onoga što bijaše klasično, kako je to razdoblje označavao njegov učitelj Jacob Burckhardt u djelu Ciceron (1855), jer je za najveće genije renesanse kakvi su bili Bramante, Michelangelo i Vignola karakteristično da se već u zreloj dobi njihove klasičnosti mogla naslutiti pojava novoga stila. Zato je barok moguće misliti i kao jednu etapu kontinuiranoga razvoja renesansne klasike u klasicizam, inače dominantan pravac u drugim, neknjiževnim umjetnostima tijekom druge polovice XVIII. stoljeća. S druge pak strane, barok bi se mogao tumačiti i kao rođenje nečeg novog, a ne kao (hipertrofirani) nastavak pozne renesanse u drukčijem ruhu i izgledu (u ostalim umjetnostima taj će izgled prevladati od 1580. nadalje). Takav stav nije daleko od istine. Novina se u to vrijeme doista jasno očitovala u doživljaju i izrazu, budući da se posvuda govorilo o stilo moderno (ne i o „baroku”, razumije se, jer je ta riječ kasnijeg datuma). Otuda u historijskoj formaciji baroka zarana možemo zapaziti dvosmisleno preplitanje kontinuiteta i diskontinuiteta. Na tome se preplitanju ujedno temelji i afirmativni karakter cjelokupnog razdoblja. Wölfflin, primjerice, iznosi i tvrdnju da je u „modernom” (što će reći: baroknom) stilu težnja za uvođenjem vlastite 
nepogrješivosti možda i naglašenije prisutna negoli u drugim velikim povijesnim stilovima (usp. Wölfflin 1888: 12).

Usprkos prvotnom odbacivanju, barok je kao novodefinirani period postao pravi fascinosum. Ubrzo su se tim imenom počela označavati i djela jezične umjetnosti. U književnoj povijesti, termin „barok” prvi je upotrijebio Fritz Strich u raspravi „Der lyrische Stil des 17. Jahrhunderts” (1916), pri čemu je kao specifičnu razliku baroknog stila u poeziji isticao dinamičnu antitetičnu strukturu. ${ }^{1}$ Oduševljenje barokom još je izraženije $u$ tome što se taj termin počeo koristiti za označavanje transhistorijskog estetskog fenomena koji se, slično klasici, uvijek iznova vraća. Na to je smjerao i sam Nietzsche, koji je u glasovitoj knjizi Ljudsko, odviše ljudsko (Menschliches, Allzumenschliches) iz godine 1879. o baroku zabilježio sljedeće:

„Barokni stil nastaje svaki put pri ocvatu svake velike umjetnosti, kada očekivanja u umjetnosti klasičnog izričaja postanu prevelika; on nastaje kao nekakav prirodni događaj kojeg se gleda vjerojatno s potištenošću - budući da on prethodi noći - ali ujedno sa zadivljenošću spram njemu svojstvenih zamjenskih umjetnosti izričaja i pripovijedanja (Nietzsche 2013: 69).“

Na Nietzschea su se kasnije oslanjali mnogi teoretičari, poput Eugenia d'Orsa, koji je u svom djelu Du baroque (1935) prvi uspio sustavno razviti takvo tranhistorijsko poimanje baroka. Barok je za njega trajni tip ljudske kulture, svojevrsna čovjekova konstanta (te stoga nije vezan isključivo uz zapadnu civilizaciju), a pojavljuje se u prijelomnim kulturnim i povijesnim trenucima, koji navješćuju vremena dekadencije.

\section{Neobarok: barok kao alternativna modernost}

Koncept baroka dobio je nov zamah i novu teorijsku nadgradnju s pojavom poststrukturalizma. Najutjecajnije djelo s tim u vezi je knjiga Gillesa Deleuza pod naslovom Le pli: Leibniz et le baroque (1988). Autor u njoj pokušava smje-

Asocijacija na Wölfflina je razumljiva, jer je on bit barokne estetike objašnjavao pomoću kontrastne usporedbe s renesansom: on je, naime, bio uvjeren da je renesansa „umjetnost lijepog mirujućeg [ruhige] bitka“ (Wölfflin 1888: 22), dok se barok, nasuprot tome, odlikuje željom „da zgrabi snagom afekta“, ne poznajući „jednakomjerno okrepljenje“, već samo „uzburkanost, ekstazu, opijenost“ (Wölfflin 1888: 23). Riječju, u usporedbi s renesansom, barok nije područje statičnoga bitka, nego napetog i uznemirujućeg postajanja. 
stiti filozofsku tematizaciju baroka negdje između historijske i transhistorijske paradigme. Barok, po njegovu mišljenju, uopće nije razdoblje, nego bitno neesencijalistička i materijalistička operacija, poput kakvog beskonačnog nabiranja materije:

„Barok se ne odnosi na esenciju, već prije na neku operacijsku funkciju [function opératoire], na nekakav potez. Svagdje pravi nabore. Ne izumijeva stvari: već imamo sve nabore s Istoka, grčke nabore, rimske, gotske, klasične... No, barok nabore svija i presavija, potiskuje ih u beskonačno, nabor po nabor, nabor za naborom. Barokna crta je nabor koji ide u beskraj.“ (Deleuze 1988: 5)

Barokna operacija djeluje transverzalno, jer sobom ukršta najrazličitije estetske i literarne diskurse. U tom se smislu i autor kakav je Mallarmé može smatrati velikim baroknim pjesnikom:

„Nabor je nedvojbeno najvažniji pojam u Mallarméa, ali ne samo pojam, nego štoviše operacija, operacijski akt, koji ga čini velikim baroknim pjesnikom. Herodijada je već pjesma nabora. Nabor svijeta je lepeza ili 'u jedno usklađen nabor."“ (Deleuze 1988: 43)

Deleuzov koncept nabora djeluje kao neka vrsta sinegdohe baroka, koja smjera na radikalnu decentriranost, na „strukturu“ bez središta i oboda, u kojoj nema podjele na vanjsko i unutarnje. Na primjeru Leibniza, koji je za Deleuza filozof baroknog stila par excellence, te na primjeru arhitektonskih djela, Deleuze u baroku prepoznaje utjelovljenje nekakvog shizofrenog poretka tvorevine, interpretiranog u radikalno materijalističkoj maniri. Jednostavno rečeno: barok kao operacija, u svojoj jezgri otklanja metafizičku dihotomiju transcendencije i imanencije, iako ova ostaje u obliku privida, iluzije, tj. „stranog učinka“, jer imanencija („površina“) je toliko naborana da ostavlja dojam nečeg transcendentnog, što ona, naravno, nikako nije.

Takva je Deleuzova analiza u ozračju posljednjih nekoliko desetljeća postala značajan katalizator za različite antihistoricističke strategije kritike. Ona bi trebala eliminirati pretjerano poistovjećenje s povijesnim barokom, otvarajući prostor „novom“, „produktivnom“, „kreativnom“ baroku, odnosno baroku koji prekoračuje granice (i to ne samo u smislu prevladavanja tradicionalne linearne kronologije, periodizacije, pa čak i povijesti literature uopće), ali i dočarati neuhvatljivo presijecanje granica različitih diskursa u suvremenoj humanistici (usp. Hills 2011: 11-38). 
Iz ovoga se lako vidi sva privlačnost aktualnog kulturološkog pojma neobaroka. Kako lucidno primjećuje Carlo Ossola, „svaka generacija XX. stoljeća u baroku je prepoznala znake svoje vlastite modernosti“"(Ossola 1995: xii). Otud su pojedini autori zastupali stajalište da je u koncepcijama „novog baroka“, odnosno „neobaroka“ riječ o specifičnom „postmodernom“ preuzimanju baroknih tendencija, čija je privilegirana ishodišna točka u konkretnoj povijesnoj formaciji: u latinoameričkoj književnosti, pa i tamošnjoj umjetnosti uopće.

Jedan od utemeljitelja takvog kulturološkog poimanja neobaroka je kubanski pisac i teoretičar književnosti Severo Sarduy. Po shvaćanju tog autora, diskurs neobaroka u XX. stoljeću predstavlja emancipatorski pothvat destabiliziranja i parodiranja buržujske ekonomije. Barok, naime, u njegovu misaonom horizontu, ima izrazito subverzivnu moć. Sarduy daje zanimljivu analogiju: slično baroknoj kozmologiji, u kojoj uspostavljena elipsa (Kepler) subvertira krug, i baroknu umjetnost možemo promatrati i razumjeti kao sredstvo potkopavanja modernog kapitalističkog sustava. Keplerova elipsa tu služi kao metafora neobaroknog postupka decentriranja (usp. Sarduy 1975: 167).

Poput Sarduya, i drugi kubanski pisac, José Lezama Lima, tvrdi da „američki“ barok nema ničeg zajedničkog s protureformacijom, već se nadovezuje na protukonkvistu (contraconquista), te je zato, u svojem jedru, antikolonialni fenomen. Lezama Lima se, dakako, pridružuje glasovitom stavu Aleja Carpentiera da je Amerika od pamtivijeka barokna, na što ukazuju i američke civilizacije koje prethode Kolumbovu dolasku (usp. Lezama Lima 1993: 79-106).

Analiza neobaroka u sljedećem koraku može se dovesti u vezu sa suvremenom kapitalističkom kulturom spektakla. To je osobito tematizirano u djelima Christine Buci-Glucksmann, koja uspostavlja diskurs o novom baroku oslanjajući se na paradigme vizualnog (zrenja, pogleda) i na teoretičare kao što su Walter Benjamin, Freud i Lacan. Francuska autorica uspoređuje teatralizaciju suvremene društvene sfere s teatralizacijom povijesnog baroka. U baroknom razumu (Raison), koji predstavlja princip cjelokupne koncepcije baroka, tijesno se prepliću teatralizacija egzistencije i ambivalentna logika (usp. Buci-Glucksmann 1986).

William Egginton osim izraza neobarok, koji po njegovu mišljenju još uvijek može biti obilježen latentnim imperijalizmom, koristi i svoju kovanicu coloneobaroque (Egginton 2010: 69). Njome se ne označava povratak povijesnom baroku, već estetičkoj strategiji koja se nadahnjuje tom formacijom, oviseći o 
filozofskim pretpostavkama euroameričke modernosti i zapadne novovjekovne ontologije. Neobarok kao coloneobaroque bio bi, dakle, nekakva hibridna „staro-nova" postkolonijalna estetika, koju Egginton opisuje tipičnim deleuzovskim pojmovnim instrumentarijem: za tu je estetiku karakteristično paradoksalno dvojstvo, nepomirljiva napetost između centrifugalne i centripetalne sile, između molarnog i molekularnog (Egginton 2010: 75). Nije riječ o tome da je barok ideološki, a neobarok subverzivan koncept; i baroknu i neobaroknu estetiku trebamo misliti sukladno nereduktibilnom povijesnom razumijevanju. Taj okvir stvara najvažniji problem zapadne modernosti, koja za Eggintona predstavlja „kazališnu“ disociaciju između privida i istine. Ona se razotkriva u klasičnim primjerima barokne kulturne produkcije, u tehnikama poput trompe l'oeil, mise en abyme i anamorfoze. Osobito je značajna potonja, koja označava poznatu slikarsku manipulaciju perspektivom, pri čemu se događa da se slike pojavljuju ili posve iščezavaju, ovisno o točki gledišta promatrača. Brisanje razlika između realnoga i iluzornoga - što može izazvati šok, potres, ali i užitak u isti mah - bilo bi, dakle, (neo)barokna strategija par exellance.

Otuda proistječe i projekt neobaroka kao konstrukcije alternativne modernosti novoga svijeta, nekakve disonantne, heterogene modernosti koju nikakva teorijska sinteza ne može savladati, jer se pojavljuju „alternative znanstvenim dualizmima” (Kaup 2012: 33) koje postaju glavno filozofsko uporište postkolonijalne estetike.

Zajednička odlika takvih „filozofskih“, polifonih pojmova baroka uglavnom je njihova političnost: u rasporu centripetalnog i centrifugalnog baroka otkriva se izlaz iz (esencijalističke) strukture suvremenog kapitalizma (usp. Roraback 2017: 255). U ovoj je rekonceptualizaciji baroka najprije problematično to što je očito riječ o aproprijaciji druge epohe, pri čemu se gubi heterološki naboj toga doba, što se najznakovitije pokazuje u potiskivanju religioznih elemenata vezanih za tu etapu u povijesti Zapada. Osim toga, historijski barok je ipak - a u tome je suglasna većina povjesničara - izrazito aficiran diskursom moći: ${ }^{3}$ naime, barokna je kultura u velikoj mjeri bila industrija spektakla, koja je najradije koristila čuvstveni kod (fantastične slike, raskošne palače, glazbu, religiju itd.), čuvajući sveopću pokornost masa apsolutističkim monarhijama. Stoga moramo smatrati paradoksalnom činjenicu da suvremeni neobarok, osobito na postko-

$\mathrm{Na}$ to da se u baroknu estetiku upisuje instancija moći upozorava i J. Lacan, u odlomku „Le baroque" svojeg znamenitog seminara Još (Encore): Le baroque c'est la régulation de l'âme par la scopie corporelle, „Barok je regulacija duše preko telesne skopije.“ (Lacan 1975: 105). 
lonijalnom teritoriju Latinske Amerike, služi za teoretizaciju nekakvog autentičnog polja političke slobode. No glavni teorijski nedostatak dane koncepcije je, po mojem shvaćanju, ipak u tome što tako definirani neobarok postaje svojevrsni catch-all izraz, koji bismo potencijalno mogli pripisati gotovo svakom književnom, odnosno umjetničkom djelu koje krasi subverzivni, antihegemonistički naboj.

\section{De Certeauov heterološki pojam baroka}

Mogući izlaz iz škripca suvremenog kulturološkog pojma (neo)baroka, po mom shvaćanju, nudi „heterološka“ analiza mističkog diskursa, čiji je autor svestrani teoretičar Michel de Certeau. U svojoj knjizi Mistična fabula ( La fable mystique), jednom od najreferentnijih djela o novovjekovnoj, tj. baroknoj mistici - premda se oznakom „barok/barokno“ uglavnom ne koristi - francuski mislilac pored ostalog pokušava pojmiti bit epohalnog prijeloma između srednjevjekovnog i modernog svijeta. Mistički diskurs pritom stavlja na razinu privilegiranog načina govora u modernosti, smatrajući ga metonimijom (par pro toto) novog vijeka kao povijesne epohe. Pokazuje se, još jednom, da je riječ o ambivalentnoj formaciji.

Mistika za Certeaua nije religiozni pokret, Crkva ili sekta, već ponajprije diskurs, koji prožima i institucije i različite teologije i duhovne tradicije. Za razliku od drugih polja spoznaje (uključujući i druge religiozne staze), mistika nema vlastito predmetno područje ni utvrđeni sadržaj; manjka joj čvrsti označitelj u pogledu arhivskih dokumenta, „tekstova”, ali i po pitanju „iskustva” (usp. de Certeau 1982: 27). Prije je posrijedi priča ili pripovijest (fr. fable), ali ne u smislu fikcije, već u etimološkom značenju riječi fari: ono o čemu se može ili treba govoriti, ono o čemu valja govoriti (usp. 1982: 23).

Mistika XVI. i XVII. stoljeća, barokna mistika, označava prijelom koji se ne događa nijekanjem, otporom prema starome poretku (srednjega vijeka), već odbacivanjem njegove dislokacije, konačnog raspada. Iako je tu na djelu nekakva žalost (deuil), koja se očituje u svijesti o gubitku harmonične i cjelovite kulture, predaje ili svijeta koji je imao pristup Smislu, Jednome, Apsolutu, u njezinu trudu oko reinterpretacije, refiguracije i reformacije naslijeđenih struktura prisutna je neka vrsta invencije, pronalaska (usp. 1982: 195). To dakako ne podrazumijeva radikalnu novinu, jer je u osnovi riječ samo o drukčijem načinu uporabe (re-employment) postojećih diskursa (usp. 1982: 29). 
U baroknoj mistici nastaje nešto novo i drugo, na temelju različitih strategija uporabe postojećega i staroga. Ekvivalente ćemo naći i u ostalim stvaralačkim poljima toga doba, „u praktičnijim poljima pisanja ili estetike, $s$ umetnošću (baroknom ili retoričkom)“ (1982: 34), što premještanjem i reinterpretacijom tradiranih ideja i predodžbi pokušavaju postići drukčije rezultate.

Između baroknog i mističnog vlada strukturna homologija; oni dijele istu genezu transcendentalnog prostora. To se jasno vidi iz de Certeauove izjave da je sve što na mističan način rađa potrebu za interpretacijom koja bi mogla ući u trag neistraživom „objektu“ toga diskursa bilo općeprisutno i prihvaćeno u „baroknoj ili flambojantskoj [flamboyante] hermeneutici, koja je slijedila retorsku tradiciju XV. stoljeća, postavši poseban 'način govora - 'stil'“" (1982: 135).

Barok stoga ne možemo ocjenjivati kao nešto posve inovativno. Barok je samo drukčija uporaba tradiranog, reinterpretacija, re-formacija, „ponovno oblikovanje" (usp. 1982: 35), koje izmiče novim totalizirajućim sintezama i koje bi moglo biti uzurpirano diskursima i institucijama moći (država, crkva itd.). Razvidno je da i barokna mistika, kao značajan dio općeg epohalnog kretanja, uvodi paradoksalan (a već spomenuti) preplet kontinuiteta i diskontinuiteta, koji stvara transcendentalni prostor moderniteta, temeljni uvjet mogućnosti njegova postojanja.

Na koji način ta mistika uopće uspijeva stvoriti i oblikovati transcendentalni prostor? Da bi mogao opstati, svaki diskurs mora ispuniti „uvjete svoje djelotvornosti“ (1982: 226), reproducirajući ih i čuvajući u isti mah. Mistički diskurs kao svoj temeljni conditio sine qua non uspostavlja nekakav singularni događaj, postupak, neko „ekscesno“ htijenje, volju (vouloir) koja prethodi svakoj spoznaji i znanju (savoir); de Certeau tvrdi da je počelo i začetak svekolikog izricanja „čudno“ performativno volo, „hoću“ (1982: 227). To volo je „apsolutno“ (ili: „absolutni volitiv“, 1982: 231), i to u etimološkom smislu od-vezanosti (ab-solviranosti) svih partikularnih odredbi (usp: 1982: 228), te je kao takav neovisan o objektnoj strani stvarnosti.

Izvorno volo je predjezično. Ono je uvjet mogućnosti mističkoga modusa loquendi in/ali agendi (usp. 1982: 26). Riječ je o prijelomu, o otvaranju prostora unutar kojeg je svako izricanje jedino i moguće. Riječ je o lingvističkom i prakseološkom a priori. Ta prvotna instancija, uvjet jezika, istodobno predstavlja - ma koliko nam to inače paradoksalno zvučalo - i njegovu nemogućnost. Ako svaki diskurs teži tome da stekne čitatelja, tj. da bude prihvaćen i čitan, 
on samom svojom danošću postulira zahtjev koji nije u stanju zadovoljiti: „Od čitaočeva razočaranja pravi modus kojim se treba latiti teksta [ils font de la déception du lecteur le mode sur lequel le texte doit être pratiqué]." Ta napetost već uvodi izvjesni „mistički“ stil u praksu teksta (stvaralačku ili recepcijsku) (1982: 230). Volo kao neiskazivo i nečitljivi a priori mističkog kazivanja tako se štiti od partikularne (samo)volje „autora“ i čitatelja - tumača.

Budući da je posrijedi čisti alteritet, posve bezobjektni događaj volje, volja se sama svija u sebe i poistovjećuje sa svojom oprekom. Htijenje postaje ne-htijenje (non-vouloir): htjeti sve (volo) i (ne) htjeti ništa (nolo) jedno je i isto (usp. 1982: 232). Volo tu, paradoksalno, postaje potpuno odricanje od volje (te samim tim i samo-volje). Ipak, odsutnost objekta htijenja naposljetku anihilira i sam volitivni (autoperformativni) subjekt. Subjekt koji se nađe na mjestu bezobjektnog htijenja nužno ispada iz kolosijeka, ek-statično iščezavajući u ništa. Ukidanje jastva u tome volo stvara prazninu čistoga htijenja, vouloir pur, korelativnog bezgraničnom „da“, koje je zapravo lišeno predmetnosti i ciljeva (usp. 1982: 239). ${ }^{4}$

Tu je, dakako, na djelu apriorno, nesubjektno „da“, o kojem govori i jedan od najvećih baroknih mističkih pjesnika, Angel Silezij: GOtt spricht nur jmmer Ja, „Bog svagda govori samo ,da“ (Angel Silezij 2012: 124, usp. de Certeau 1982: 239). Kao što iz primjedbe u izvornom tekstu doznajemo, riječ $\mathrm{Da}(\mathrm{Ja})$ je allusio ad Nomen Dei Ebraicum I A H, ,aluzija na hebrejsko Božje ime I A H“ (Angel Silezij 2012: 124). De Certeau u vezi s tim veli da isti fonem ( $J$ a sažima prijelom (coupure) i otvaranje (ouverture), i to kao Ne-Ime (Non-Nom) Drugoga i „Ja"Volje, dakle: apsolutno od-lučenost i beskonačno prihvaćanje, potvrđivanje (239). „Takva je šifra mističkog subjekta“ (de Certeau 1982: 240). Ovo Ja kao figura mističke gelassenheit (rečeno s Eckhartom, a kasnije i s Heideggerom) najposlije označava atopičnu „nutrinu“, koja je uvjet mogućnosti bilo čega, bitka i ništine. JA je jedino (ne)mjesto (un lieu/non-lieu, de Certeau: 1982: 236) zbiljske slobode. ${ }^{5}$

O ovom momentu usp. i Derridaov članak, svojevrsni hommage, „da“, Michelu de Certeau (Derrida 2018: 231-240). Članak je inače najprije objavljen na francuskom, gledaj: „Nombre de oui“, u: Qui Parle 2/2 (1988), str. 120-133.

5 Vezu s alteritetom volje de Certeau pokazuje i na primjeru isusovačkog iskustva, za koje povjesničari tvrde da je u mnogočemu temeljno za estetiku katoličkog baroka (usp. Dupré 1993: 229). Michel de Certeau primjećuje da u „voluntarizmu“ Ignacija Loyole, koji postaje bjelodan u njegovim „ekzercicijama“ (Ignacije Loyola, „Duhovne vježbe”), u onome „to, što hoću“ - id quod volo, šp. lo que quiero - dolazi do izraza dramatičan moment koji je i u Boga i u čovjeka najdublje, ali i najmanje spoznatljiv, tj. susret Božje i ljudske volje. Pritom je ključno da se id (objekta želje/ 
Ova analiza pokazuje da je de Certeaujeva teorija subjekta u eklatantnoj opreci s kartezijanskim cogitom, jer se Descartesov „moderni“ subjekt postavlja samo u odnos prema drugom/Drugome, što će reći: u modus odziva, odgovora (usp. Dosse 2002: 564). Ja postoji za drugog/Drugoga, štoviše: Ja prebiva u području „nemogućeg identiteta” s drugim/Drugim.

\section{Zaključak}

Izvjesno je da de Certeau nije razvio „novu“ teoriju modernosti (usp. Füssel 2017: 163, Maigret 2000: 541-544) - ni baroka, razumije se - već je samo umješno skrenuo pozornost na „sitne“ taktike koje otvaraju prostor za konstrukciju (i dekonstrukciju) alternativnih hermeneutičkih historiografskih projekata. Važno je prije svega to što je barokna mistika (a time i barok kao šira sociokulturna pojava) uspostavila strukturne uvjete za pojavu tipično modernih diskursa. De Certeau je, primjerice, opazio izrazitu homologiju barokne mistike i psihoanalize, moderne lingvistike i etnologije (usp. Dosse 2002: 567). Zato je Champion u pravu kad kaže da nas mistika XVI. i XVII. stoljeća nema namjeru samo interpelirati u neko drugo (barokno) doba, nego nas vodi i nečem izrazito suvremenome, „sve većoj senzibilnosti prema razlici, alteritetu, razotkrivanju nevidljivoga - i čovjeka i društva - prema nevidljivome koje ipak izmiče“ (Champion 1984: 201).

Tu se ipak otvara još jedna, dublja perspektiva, koja nije samo socioantropološka, već nam omogućuje pristup prostoru koji uvjetuje i vjeru u (posve) Drugo i nihilističko odsustvo transcendencije. Upravo ta neotklonjiva, „barokna” ambivalencija jest jedino polje čovjekove slobode, na temelju koje je moguće analizirati konkretne književne, estetske i opće kulturne pojave; neobarok se, dakle, ne da razumjeti samo kao utopijska i kvazimesijanska, (post)marksistički shvaćena alternativna modernost, kao politička subverzija koja seže onkraj racionalističke logike i esencijalizma, već prije kao ontološka mogućnost onoga kako se takva racionalistička logika uopće rađa, kakvi su doista uvjeti ne samo za formaciju diskursa moći (a time i za oblikovanje sociopolitičkoga polja), nego i za nastanak diskurzivnosti ili jezika kao takvog. Stoga je De Certeauov

volje) oslobodi fantazmatskih fiksacija i upiše se u „Temelj”, u drugost volje: „Prijelaz od volo $\mathrm{k}$ njegovu predmetu, tj. itinerarij omogućen kretanjem u kojem se najprije oslobađaju prvotne reprezentacije, na koje je htijenje praktikanta duhovnih vježbi bilo fiksirano, zadržano. U tom se pogledu konstrukcija objekta od strane nekog, htijenja' [vouloir] svrstava u red, Temelja“" (de Certeau 2005: 245). 
pristup u osnovi transcendentalan ili, kako je još Derrida zapazio, kvazitranscendentalan; ${ }^{6}$ takav pothvat nikada se ne skamenjuje u totalizirajuću jednost, te je zato fundamentalniji, jer se u njemu teorijska deskripcija usredotočuje na moć i nemoć jezika, subjekta i prakse u cjelini. Posrijedi je posebna topologija, pokušaj razumijevanja izvornoga prostora relacije između istovjetnosti i drugosti, između Ja i drugog/Drugoga, koja stoji u srži moderne (neo-barokne) subjektivnosti. Zbog toga možemo kazati da je barok kao transliterarni (kulturološki) koncept (makar na tragu de Certeauove misli) razumljiv jedino heterološki. Drugim riječima, u području (neo)baroka ne nailazimo najprije na spregu između voluntarističkog i potencijalnog, između htjeti i moći izricati, već se temeljna crta ove umjetnosti povlači u obratnome smjeru: u otvorenosti za to da nas drugi/Drugi izrekne i oslovi.

\section{LITERATURA}

Angel Silezij. 2012. Kerubinski popotnik. Gorazd Kocijančič, Vid Snoj i Alen Širca, prev. Ljubljana: Kud Logos.

Barner, Wilfried. 2002. Barockrhetorik. Untersuchungen zu ihren geschichtlichen Grundlagen. Tübingen: Niemeyer.

Buci-Glucksmann, Christine. 1986. Folie du voir. De l’esthétique baroque. Paris: Galilée.

Champion, Françoise. 1984. La fable mystique et la modernité. Archives de Sciences Sociales des Religions 58/2, 195-203.

de Certeau, Michel. 1982. La fable mystique, 1, XVIe-XVIIe siècle. Paris: Gallimard.

de Certeau, Michel. 2005. Le lieu de l'autre. Histoire religieuse et mystique. Luce Giard, ur.

Paris: Gallimard/Seuil.

Deleuze, Gilles. 1988. Le pli: Leibniz et le baroque, Paris: Minuit.

Derrida, Jacques. 2008. A Number of Yes. U: Psyche: Inventions of the Other, zv. 2. Peggy Kamuf i Elizabeth Rottenberg, ur. Stanford, CA: Stanford University Press, 231-240.

Dosse, François. 2002. Michel de Certeau. Le marcheur blessé. Paris: La Découverte.

Dupré, Louis. 1993. Passage to Modernity. An Essay in the Hermeneutics of Nature and Culture, New Haven: Yale University Press.

Egginton, William. 2010. The Theater of Truth: The Ideology of (Neo)Baroque Aesthetics. Stanford, Calif.: Stanford University Press.

Füssel, Marian. 2017. Zur Aktualität von Michel de Certeau. Einführung in sein Werk. Wiesbaden: Springer.

Svoju oznaku kvazitranscendentalnosti Derrida preciznije određuje ovako: kvazitranscendentalnost „može biti samo fikcijska ili fabulativna, posve predana priloškoj oznaci quasi“ (Derrida 2008: 239), što prije svega znači da nikada nije prisutna kao takva, već prethodi svakom prisustvu i bitku. 
Hills, Helen. 2011. The Baroque: The Grit in the Oyster of Art History. U: Rethinking the Baroque. Helen Hills, ur. Farnham: Ashgate, 11-38.

Kaup, Monika. 2012. Neobaroque in the Americas. Alternative Modernities in Literature, Visual Art, and Film. Charlottesville: University of Virginia Press.

Lacan, Jacques. 1975. Encore. Le séminaire, livre XX. Jacques-Alain Miller, ur. Paris: Seuil, 1975.

Maigret, Éric. 2000. Les trois héritages de Michel de Certeau. Un projet éclaté d’analyse de la modernité. Annales ESC 55/3, 511-549.

Nietzsche, Friedrich. 2013. Ljudsko, odviše ljudsko. Knjiga za slobodne duhove, svezak 2. Berislav Podrug, prev. Zagreb: Demetra.

Ossola, Carlo. 1995. In limine. U: L' anima in barocco. Testi del seicento italiano. Carlo Ossola, ur. Torino: Scriptorium.

Roraback, Erik S. 2017. The Philosophical Baroque: On Autopoietic Modernities. Leiden: Brill. Sarduy, Severo. 1975. Barroco, Paris: Gallimard.

Wölfflin, Heinrich. 1888. Renaissance und Barock: eine Untersuchung über Wesen und Entstehung des Barockstils in Italien. München: T. Ackermann. 


\title{
BAROQUE AS A CULTURAL CONCEPT
}

\begin{abstract}
Alen Albin ŠIRCA

Faculty of Arts, University of Ljubljana

Aškerčeva 2

1000 Ljubljana, Slovenia

alen.albin.sirca@ff.uni-lj.si
\end{abstract}

After Heinrich Wölfflin introduced the notion of Baroque in the history of art, the term rapidly expanded to all areas of humanities, including the realm of literary studies. In parallel with this historical understanding, the transhistorical understanding of Baroque as a decadent style that can occur in every epoch was developing, at least from Nietzsche's era on. In the last decades, literary theory has developed the term "Neo-Baroque" in order to clarify the construction of alternative histories of modernity that would be immune to the essentialist logic of modern capitalism. In the article, I draw on the "heterologic" interpretation of modernity developed by the French theoretician Michel de Certeau. In his work La Fable mystique (1982), he argues that Baroque mystical literature does not establish the radical rupture from the Middle Ages, but rather a new mode of uses (re-employment) of existing discourses, which avoids any closure within the frames of institutions. The precondition of such discursive strategies is a special relationship to radical alterity. Such a relationship does not foster stable Cartesian subjectivity, but rather a subject that is for the other/Other. The assumption that mystical literature functions as a symptom of modernity in general paves the way to an insight into the originary, "atopic" space that goes beyond the mere social and political projects of emancipation. What is at stake here is a kind of transcendental understanding of modernity as a condition of the possibility of the subjectivity, discursiveness and practice, which are focused on a heterological ethics.

Keywords: Baroque, Neo-Baroque, modernity, alterity, Michel de Certau 